\title{
Online and Offline Social Activity and Sociability Effects on Wellbeing and Social Influence: A “Spillover” Effect
}

\author{
Rita Mano, Dennis Rosenberg \\ Department of Human Services, University of Haifa, Haifa, Israel \\ Email: ritamano@research.haifa.ac.il
}

How to cite this paper: Mano, R., \& Rosenberg, D. (2021). Online and Offline Social Activity and Sociability Effects on Wellbeing and Social Influence: A "Spillover" Effect. Advances in Applied Sociology, $11,48-63$.

https://doi.org/10.4236/aasoci.2021.111005

Received: December 8, 2020

Accepted: January 26, 2021

Published: January 29, 2021

Copyright $\odot 2021$ by author(s) and Scientific Research Publishing Inc. This work is licensed under the Creative Commons Attribution International License (CC BY 4.0).

http://creativecommons.org/licenses/by/4.0/

\begin{abstract}
In this study, we explore the effect of online and offline sociability on wellbeing and social influence reports. We draw upon happiness studies, communication theories, and the social diversification hypothesis to test the effect of online/offline sociability on wellbeing and social influence. We use a secondary level analysis $(\mathrm{N}=532)$ from a representative US population (49\% women) published by the Princeton Institute for Internet studies. The findings indicate that online sociability increases whereas offline sociability has no effect on either wellbeing or social influence. Nonetheless, higher online sociability moderates the relationship between the offline sociability and lower wellbeing and social influence. We conclude that online sociability has a stronger direct effect as well as a spillover effect on offline wellbeing and social influence.
\end{abstract}

\section{Keywords}

Online/Offline Social Activity, Wellbeing, Social Influence

\section{Introduction}

The rapid pace of life in the 21th century has limited the time available for nurturing our sociability needs in the traditional "physical" social space (Green \& Brock, 2008). The evolution of online technology and introduction of social media has marked a new era of connectivity and sociability that enabled individuals to be involved in a social exchange process and share common interests, information and concerns with others (Tufekci, 2008), without leaving own home or work/study place. Online channels prompt and facilitate creation of and involvement in the social "space" (Das \& Sahoo, 2011). These channels may have increased individuals' levels of happiness affecting their wellbeing and social in- 
fluence (Spahn, 2015). Yet, little attention has been addressed to how online sociability, which is measured in a current study by a set of online social activities, affects individual happiness the way these manifest in individual evaluations of wellbeing $(W B)$ and social influence $(S I)$. In the present study, we tap into the link between two distinct forms of happiness evaluations, i.e. wellbeing ( $W B$ ) and social influence (SI) (Anand, 2016), and online (ONS) and offline (OFS) sociability. We consider the possibility that variations in the use of technology and socio-economic variations shape the level of influence of ONS and OFS on WB and SI. We also consider the possibility of a "spillover effect" between ONS and OFS (Mesch et al., 2012). The "spillover" effect will manifest in that individuals using ONS seeking to increase WB and SI will be able to capitalize on the online gains in sociability to increase OFS sociability. In order to do so, we combine "user-technology interface" communication studies models and the social diversification hypothesis (Mesch et al., 2012) and consider the possibility that a "spillover" conceptualization enables to clarify the relationship between ONS and OFS on one hand and WB and SI on the other. We present a summary of the main communication and sociology perspectives addressing the significance of online platforms for individuals and develop a set of hypotheses to compare ONS and OFS regarding their effects on WB and SI.

\section{Literature Review}

The landscape surrounding the role of technology in promoting happiness is broad covering multiple disciplines. In order to address the relationship between technology and happiness, we focus on Spahn's (2015) statement that "the best types of technology for human happiness might thus not be those that try to "control the external circumstances" [but] when they can take away obstacles rather than contribute actively to true meaningful happiness ..." (p. 78). This statement enables to distinguish between the person-related and the circumstance-directed types of happiness. The distinction is helpful in our comparison between: a) ONS effects on WB and b) OFS effects on WB and SI. At first, we present a summary of central user-technology interface models and proceed with the social diversification approach.

\section{Communication perspective}

Uses and Gratifications ( $U \& G$ ) theory suggests that people seek to satisfy their social and psychological needs using media (Heravi et al., 2018). According to this theory, people actively and purposefully choose media sources based on their motivations (Bondad-Brown et al., 2012). In line with that, those who lack considerable levels of sociability may be more likely to view ONS as an effective, "functional", and gratifying tool for increasing social networking. Consequently, they will optimize personal gains in terms of group affiliation and belonging and possibly information gathering (Ross et al., 2009). Indeed, individuals who use ONS for authentic self-presentation (Reinecke \& Trepte, 2014) are likely to increase their self-esteem (Ellison et al., 2007). Yet, when the amount of ONS use 
increases above certain levels, then self-esteem (Kalpidou et al., 2011), as well as WB, tend to decrease (Fioravanti et al., 2012; Koles \& Nagy, 2012). As a result, different users may be more or less willing to use ONS and OFS according to their perceptions of "usability" of the online and offline realms to achieve their desired levels of sociability. One possibility, for example, is that older individuals and possibly those with higher socioeconomic status will be more willing to use ONS. Accordingly, we hypothesize that:

H1a: Individual-level variations will generate variation in ONS.

H1b: Individual-level variations will generate variation in OFS.

Media System Dependency theory (Kim \& Jung, 2017) addresses the extent to which individuals will use ONS. Online communication increases social support, reduces social anxiety, increases self-esteem and reduces social isolation (Davis, 2012; Dolev-Cohen \& Barak, 2013; Gross, 2009; Ko \& Kuo, 2009; Selfhout et al., 2009; Valkenburg et al, 2006). Individuals who will to depend upon a specific media to meet their goals are more likely to use this media more often (Grant et al., 1991). As a result, it is possible that sociable individuals will be likely to continue and increase use of ONS to increase WB and SI. Accordingly, we hypothesize that:

H2: Higher frequency of Internet use will increase ONS.

Activation theory expands the Media System Dependency theory and introduces the "level" of activity as a factor that refines the extent to which individuals take "conscious" actions to achieve their goals. The more frequently individuals use a particular means to achieve sociability, the greater the likelihood they will continue to strive for this particular goal by reusing their success and transmitting it to other individuals by participating in online discussions, gossiping, commenting, playing or sharing different activities. Activation Theory is of particular interest when we seek to differentiate between ONS and OFS because it is easier to engage in ONS than OFS. Nevertheless, reported innate dangers in ONS overuse range from increased ineternalization of problems (Rauch et al., 2014) to personality disorders (Rosen et al., 2013). These dangers may affect evaluations of WB and SI. Accordingly, we hypothesize that:

H3: Higher frequency of Internet use will decrease OFS.

Both the Media System Dependency approach and Activation theory assume that communication tools affect our sense of time and space and even more so, our feelings of belonging and relatedness (Shklovski et al., 2008). In their pioneer study on belonging, Baumeister and Leary (1995) contend that all human beings need a certain minimum quantity of regular and satisfying social interactions. When individuals are accepted, welcomed, or included, they feel positive emotions such as happiness, calm, and satisfaction. Belonging and social connectedness are therefore regarded as "needs", not just desires, affecting our awareness and shaping our social relationships.

\section{Sociological perspective}

Social belonging involves a sense of relatedness that goes beyond mere belonging and manifest in a complex set of relationships that provide social feed- 
back, self-validation, and shared experiences. Such experiences, even at minimal levels of social connectedness, affect important aspects of self (Walton et al., 2012) and shape our awareness information system (Markopoulos, 2009). While belonging is "subjective" in nature, its consequences are "objective" affecting the quality of our daily life (Burke \& Kraut, 2016), because it captures and shapes a wide range of social experiences. Some interactions involve shaping of our perceptions and appraisal of social position (Baumeister \& Leary, 1995) whereas others capture our molding of "others" including the feelings of togetherness (Van Baren et al., 2004) that is disconnected from the external environment (Markopoulos, 2009). Assessing ONS and OFS effects on WB and SI necessitates therefore, to address the "context" of ONS and OFS use.

The Social Diversification Hypothesis (hereafter SDH) expands the theoretical background provided by the abovementioned communication and technology approaches and illustrates how applying a social science perspective increases our potential to compare the sociability patterns of individuals and communities (Mesch et al., 2012). SDH suggests that greater use of ONS expands the alternatives for entering into an extended span of social interactions for sociable individuals, but engaging in ONS in the virtual realm will not necessarily diminish the importance and use of OFS and existing interactions in the physical realm (Mano, 2015; Mesch et al., 2012). In fact, both ONS and OFS promote the generation and maintenance of connections between people with similar interests in setting and maintaining close ties (Markopoulos, 2009). As a result, ONS dissolve sociability barriers caused by separation in time and space (Raacke \& Bonds-Raacke, 2008) and similarly to OFS extend the level of sociability between members of social networks (Hsu et al., 2011) and families (Romero et al., 2007). More specifically, SDH considers the extent to which individual needs for sociability are attained equally by ONS and OFS (Hampton et al., 2011).

SDH accentuate the irreversible role of the virtual realm in creating online communities among those who are "remote" from a physical social space. SDH also establishes that the differential use of ONS and OFS is dependent on the degree to which one belongs and feels connected to a larger group (Yamamoto, 2011) and personal skills (Neuman et al., 2011). The difference in motivations reflect the degree to which individuals feel connected to a larger group (Yamamoto, 2011), and/or trust in virtual communities (Hsu et al., 2011). These factors generate and facilitate group identity (Ren et al., 2012; Shen et al., 2010) especially when sociability interferes with sense of identification, loyalty and satisfaction within a group setting (Pai \& Tsai, 2011). Recent evidence shows, for example, that while some individuals report they strengthen social relationships via Facebook (Papacharissi \& Mendelson, 2011), others claim that OFS is of higher quality and generates greater WB (Davis, 2012; Ko \& Kuo, 2009; Selfhout et al., 2009).

Moreover, initial differences in individuals' socioeconomic context and WB and SI may affect the extent and scope of ONS relative to OFS (Raacke \& Bonds-Raacke, 2008). Gender, for example, was shown to moderate the rela- 
tionship between SI and behavior (Kwon et al., 2014). Women are reported to be more likely to be socially influenced than men (Eagly, 1983) and more active in online social participation (e.g., Bouhnik \& Mor, 2014; Ellison et al., 2007; McAndrew \& Jeong, 2012). Moreover, women have different motivations (Stefanone et al., 2012; Thelwall, 2008) for using ONS than men. Age is an additional variable because older age may reduce possibilities of ONS whereas younger age increases both ONS and OFS (Hampton et al., 2011; Schöbel et al., 2016). Parental status is also an important context effect since the presence of younger children at home reduces the opportunities for OFS. Such "context" effects affect the preference for using ONS in relation to OFS and vice versa (Mano, 2014; Mesch et al., 2012). This is especially important because individuals differ in their reasons and motivations for engaging with a medium (Mesch \& Talmud, 2007).

Accordingly, we hypothesize that:

H4: The effect of ONS on WB will be greater than that of OFS after controlling for social context effects.

H5: The effect of ONS on SI will be greater than that of OFS after controlling for social context effects.

\section{Methods}

Sample: The present study is a secondary analysis based on the Internet and the American Life Project from Princeton Survey Research Associates (PEW) released in 2012. From the initial 6270 respondents, sample of individuals that reported being active both online and offline was selected $(\mathrm{N}=532$, of them, $49 \%$ were women).

Dependent variables: Wellbeing $(W B)$ was measured as a sum of scores on the two following items: "Are you satisfied or dissatisfied with the way things are going in this country today" (" 1 " = satisfied; " 0 " = dissatisfied), and "Are you satisfied or dissatisfied with the way things are going in the community where you live today?" ("1" = satisfied; "0" = dissatisfied). Social influence (SI) was measured by the following item: "Overall, how much impact do you think people like you can have in making your community a better place to live?" (with responses ranging from " 1 " = no impact at all, to " 5 " = a major impact).

Independent variables: Online sociability (ONS) was measured as a sum of reports on the items representing the extent of performing four social online activities during the 12 months prior to the survey: posting comments on a website or blog about a political or social issue, posting pictures on the Internet about a political or social issue, posting a video on the Internet about a political or social issue, and writing about a political or social issue in own blog (Cronbach's $\alpha$ $=.741)$. Offline sociability $(O F S)$ was measured as a sum of reports on the eight items representing the extent of performing social offline activities during the 12 months prior to the survey: attending a political rally or speech, attending an organized protest, attending a political meeting about local, town or school affairs, working or volunteering for a political party or candidate, making a speech about a community or political issue, being an active member of any group try- 
ing to influence public policy or government (not including a political party), participating in a walk, run or ride for a cause, and working with fellow citizens to solve a problem in your community (Cronbach's $\alpha=.8$ ).

Context (control) variables: Frequency of Internet use was measured by a single item asking whether respondents have used the Internet. The responses ranged from " 5 " = several times a day, to " 1 " = not often or never (items were reversed)). Age was measured in years. Gender was a dichotomous variable, with women as a reference category. Employment was a binary variable, whereas people working full-time coded as " 1 " and those in other statuses as a reference category. Education was measured by a last grade or class completed in school. Marital status was a dichotomous variable, with people who are not married for any reason as a reference category. Parental status was a dichotomous variables, with respondents who were not parents or guardians to any children under age 18 in the household as a reference category.

\section{Results}

We proceed with the research analysis as follows. First, we present the correlation table for the examined variables. Second, we present the means difference test for the examined variables. Third, we present a model predicting WB and SI while controlling for the effect of context variables, including socioeconomic differences and variations in frequency of use (Table 1).

The findings shown in the table provided support for the significance of the interrelations between the examined main variables. First, ONS was related to increased estimations of WB $(r=.16, p<.001)$ as well as of SI $(r=.25, p<.001)$. Similarly, OFS was related to increased WB $(r=.13, p<.001)$ as well as SI $(r$ $=.18, p<.001)$. Moreover, a significant effect emerged concerning the effect of frequency of Internet use. Higher frequency of use was significantly related both to WB $(r=.09, p<.001)$ (Heo et al., 2015) and to SI $(r=.13, p<.001)$. In addition, higher frequency of Internet use was significantly correlated with both ONS $(r=.2, p<.001)$ and OFS $(r=.2, p<.001)$. Therefore, the likelihood that Hypothesis 2 is supported is high but further analysis is needed to assess Hypothesis 3.

Table 1. Zero order correlations for frequency of internet use, online sociability, offline sociability, wellbeing, and social influence.

\begin{tabular}{|c|c|c|c|c|c|}
\hline & 1 & 2 & 3 & 4 & 5 \\
\hline 1. Frequency of Internet use & - & $.088^{* * *}$ & $.130^{\star * *}$ & $.198^{* * *}$ & $.204^{* * *}$ \\
\hline 2. Wellbeing & & - & $.131^{\star * *}$ & $.155^{\star * *}$ & $.133^{* * *}$ \\
\hline 3. Social influence & & & - & $.251^{\star * *}$ & $.178^{* * *}$ \\
\hline 4. Online sociability & & & &.- & $.404^{\star \star \star x}$ \\
\hline 5. Offline sociability & & & & & \\
\hline
\end{tabular}


The findings indicate that indeed the Internet serves to support offline as well as online relationships rather than merely develop and maintain online sources of sociability. In addition, the results clearly indicated a high probability that ONS and OFS provide a central venue in increasing both wellbeing and social influence. Equally important is the finding that ONS was correlated with OFS ( $r$ $=.4, p<.001)$, indicating that online and offline sociability are interchangeable and complementary forms of connecting with existing friends as well as acquiring new ones (Mesch et al., 2012). These findings present a preliminary assessment of our hypotheses $\mathrm{H} 1$ and $\mathrm{H} 2$ because they indicate that individuals are using different means to facilitate their sociability and WB.

Next, we conducted a t-test to assess differences in the use of ONS and OFS while considering the context variables, including a set of socio-demographic effects and frequency of use.

The findings in Table 2 indicate that differences in ONS and OFS are evident for all aspects of context variables. Differences in age, education, employment status, marital status and parental responsibilities were all shown to be significant in generating differences in ONS and OFS (except for the difference in parental status regarding the ONS). This evidence clearly points to the possibility that differences in wellbeing and social influence stem from initial differences in the "context" of ONS and OFS users. These findings indicate that while we can be quite certain about the validity of $\mathrm{H} 2$ yet, further analysis is needed to assess to what extent according to Hypothesis 1a remains valid when context (socioeconomic factors) are included in our model.

On the next stage, we estimated a linear regression model to predict the direct effects of the ONS and OFS on the wellbeing and social influence dependent variables while controlling for the context (socioeconomic factors) and control effects (frequency of use) (Table 3).

The findings suggest that ONS was significantly associated with social influence $(b=.15 ; p<.001)$ and wellbeing $(b=.16 ; p<.01)$. These associations are

Table 2. T-test differences between online and offline sociability by context variables.

\begin{tabular}{|c|c|c|c|c|c|c|c|c|}
\hline & \multicolumn{4}{|c|}{ Offline sociability } & \multicolumn{4}{|c|}{ Online sociability } \\
\hline & $\begin{array}{l}\text { Sum of } \\
\text { squares }\end{array}$ & df & $\begin{array}{l}\text { Mean } \\
\text { square }\end{array}$ & $\mathrm{F}$ & $\begin{array}{l}\text { Sum of } \\
\text { squares }\end{array}$ & $\mathrm{df}$ & $\begin{array}{l}\text { Mean } \\
\text { square }\end{array}$ & $\mathrm{F}$ \\
\hline Age & 2156.935 & 54 & 27.303 & $4.890^{\star * *}$ & 176.001 & 54 & 3.259 & $2.890^{\star * *}$ \\
\hline Gender & 69.699 & 1 & 69.699 & $11.921^{* * *}$ & 10.306 & 1 & 10.306 & $7.909^{* * *}$ \\
\hline Family status & 414.204 & 6 & 59.172 & $10.207^{* * *}$ & 26.002 & 6 & 4.334 & $3.365^{\star *}$ \\
\hline Employment & 1008.400 & 5 & 144.057 & $25.263^{* * *}$ & 38.403 & 5 & 7.681 & $6.071^{* * *}$ \\
\hline Education & 3542.140 & 6 & 506.020 & $95.515^{\star * *}$ & 122.029 & 6 & 20.338 & $18.038^{\star * *}$ \\
\hline Parental status & 889.627 & 2 & 444.814 & $77.809^{\star * *}$ & .695 & 2 & .695 & .527 \\
\hline $\begin{array}{l}\text { Frequency of } \\
\text { Internet use }\end{array}$ & 1822.170 & 17 & 82.826 & $14.328^{* * *}$ & 129.744 & 17 & 7.632 & $6.721^{\star * *}$ \\
\hline
\end{tabular}

Note. ${ }^{*} p<.05,{ }^{* *} p<.01,{ }^{* *} p<.001$. 
Table 3. Regression standardized and unstandardized coefficients for online and offline sociability effects on wellbeing and social influence.

\begin{tabular}{ccccccccc}
\hline & \multicolumn{3}{c}{ Social Influence } & \multicolumn{5}{c}{ Wellbeing } \\
\cline { 2 - 8 } & $\mathrm{B}$ & Std. Error & Beta & $\mathrm{t}$ & $\mathrm{B}$ & Std. Error & Beta & $\mathrm{t}$ \\
\hline (Constant) & 1.098 & .308 & & $3.570^{* * *}$ & 1.382 & .642 & & $2.154^{* * *}$ \\
Age & .009 & .003 & .126 & $2.834^{* *}$ & .021 & .005 & .197 & $4.496^{* * *}$ \\
Gender & -.231 & .090 & -.106 & $-2.559^{* *}$ & -.150 & .132 & -.046 & -1.135 \\
Family status & -.005 & .024 & -.010 & -.211 & .153 & .035 & .212 & $4.367^{* * *}$ \\
Employment & .099 & .035 & .123 & $2.833^{* *}$ & .195 & .051 & .162 & $3.800^{* * *}$ \\
Education & .066 & .033 & .094 & $1.993^{*}$ & .175 & .049 & .167 & $3.597^{* * *}$ \\
Parental status & .200 & .102 & .090 & 1.958 & -.854 & .150 & -.258 & $-5.683^{* * *}$ \\
$\begin{array}{c}\text { Frequency of } \\
\text { Internet use }\end{array}$ & -.021 & .012 & -.082 & $-1.726^{*}$ & .034 & .017 & .092 & $1.954^{* *}$ \\
$\begin{array}{c}\text { Offline } \\
\text { sociability }\end{array}$ & -.029 & .023 & .056 & 1.248 & -.038 & .034 & -.049 & -1.121 \\
$\begin{array}{c}\text { Online } \\
\text { sociability }\end{array}$ & .151 & .041 & .160 & $3.706^{* * *}$ & .159 & .060 & .113 & $2.647^{* *}$ \\
\hline
\end{tabular}

Note. ${ }^{\star} p<.05,{ }^{* *} p<.01,{ }^{* * *} p<.001$.

especially significant considering the control the proposed model exerts over a large set of "context" variables. It is possible that individuals with greater time and space constraints were more likely to turn to ONS as a source of wellbeing and social influence.

As to other associations, for example, individuals who are parents reported lower level of WB $(b=-.85, p<.001)$. This effect, though, was "corrected" when we added ONS into the model equation. The "constraining" effect of parental status on WB is then diminished because ONS had a positive effect both for WB $(b=.16 ; p<.01)$ and for SI $(b=.15 ; p<.001)$. Similarly, the constraining effect of gender that prevents women from reporting high SI $(b=-.23 ; p<.01) \mathrm{im}-$ proved when ONS are involved. In addition, age was found positively associating with both WB $(b=.02 ; p<.001)$ and SI $(b=.01 ; p<.01)$. Education was also found positively associating with both $\mathrm{WB}(b=.18 ; p<.001)$ and SI $(b=.07 ; p$ $<.05)$. Finally, employed full-time exhibited both greater WB $(b=.2, p<.001)$ and SI $(b=.1, p<.01)$.

The revealed effects indicate a high probability that individuals really need more virtual space to satisfy their sociability needs and hence to increase their levels of happiness. The positive impact of ONS on WB and SI is, however, not because individuals access the internet and the virtual realm of sociability more often. Nonetheless, the frequency of Internet access is a significant factor in the link between OFS and WB estimations suggesting that OFS increases through ONS. Finally, we assess the overall fit for the proposed models predicting WB and SI.

The findings in Table 4 point to an overall good fit for the proposed models. 
Table 4. Regression standardized and unstandardized coefficients for online and offline sociability effects on wellbeing and social influence.

\begin{tabular}{ccccccccccc}
\hline & $\mathrm{R}$ & $\begin{array}{c}\mathrm{R} \\
\text { Square }\end{array}$ & $\begin{array}{c}\text { Adjusted } \\
\text { R square }\end{array}$ & $\begin{array}{c}\text { Std. error } \\
\text { of the } \\
\text { estimate }\end{array}$ & $\begin{array}{c}\text { R square } \\
\text { change }\end{array}$ & $\begin{array}{c}\mathrm{F} \\
\text { change }\end{array}$ & df1 & df2 & $\begin{array}{c}\text { Sig. } \\
\text { F change }\end{array}$ \\
\hline $\begin{array}{c}\text { Individual } \\
\text { level variations }\end{array}$ & $.343 \mathrm{a}$ & .118 & .108 & 1.52875 & .118 & 11.423 & 7 & 598 & $.000^{* * *}$ \\
$\begin{array}{c}\text { Offline } \\
\text { sociability }\end{array}$ & $.343 \mathrm{~b}$ & .118 & .106 & 1.52999 & .000 & .027 & 1 & 597 & .870 \\
$\begin{array}{c}\text { Online } \\
\text { sociability }\end{array}$ & $.358 \mathrm{c}$ & .128 & .115 & 1.52235 & .010 & 7.008 & 1 & 596 & $.008^{* *}$ \\
$\begin{array}{c}\text { Individual } \\
\text { level variations }\end{array}$ & $.260 \mathrm{a}$ & .068 & .057 & 1.054 & .068 & 6.188 & 7 & 598 & $.000^{* * *}$ \\
$\begin{array}{c}\text { Offline } \\
\text { sociability }\end{array}$ & $.282 \mathrm{~b}$ & .079 & .067 & 1.048 & .012 & 7.664 & 1 & 597 & $.0066^{* *}$ \\
$\begin{array}{c}\text { Online } \\
\text { sociability }\end{array}$ & $.316 \mathrm{c}$ & .100 & .086 & 1.037 & .021 & 13.737 & 1 & 596 & $.000^{* * *}$ \\
\hline
\end{tabular}

Note. ${ }^{*} p<.05,{ }^{* *} p<.01,{ }^{* * *} p<.001$.

First, the findings indicate that individual level variations provided a solid set of predicting variables, accounting for almost $35 \%$ of the variance in the prediction of WB. A small but significant addition to WB prediction came from the impact of ONS $\left(R^{2}=.36\right)$ after controlling both for individual level variations and for OFS. Yet the impact of OFS showed no effect whatsoever. For SI, however, a different situation emerged. Here individual level variations provided a reasonable (lower than WB) contribution explaining only $26 \%$ of the variance. However, the contribution of both OFS ( $R^{2}$ change $\left.=.08\right)$ and ONS $\left(R^{2}\right.$ change $\left.=.10\right)$ was significant. The results indicate that individuals who were already involved in offline sociable exchanges also added online channels to maintain SI and hence expand and/or strengthen existing social ties (Mano, 2014; Mesch et al., 2012). Hence, both Hypothesis 4 and Hypothesis 5 were confirmed. This indicates that the effect of ONS on WB is greater than that of OFS, and that the effect of ONS on SI is greater than that of OFS after controlling for social context effects.

\section{Discussion}

Sociability is an important aspect in the lives of individuals, which creates feeling of mattering and increases wellbeing (Chopik et al., 2017). In addition, digital technologies have become an integral part of everyday life (Barnard et al., 2013). Therefore, sociability on the web has become so effective that it seems to have managed to "catch" up with the traditional physical and unmediated social space. "Networked publics" have provided a large space for connectivity among individuals by increasing their sense of belonging and their ability to express 
opinions that otherwise would have been restricted by time or space limitations. In this study, we tapped into the link between two distinct forms of happiness evaluations, i.e. wellbeing (WB) and social influence (SI) (Anand, 2016), and online (ONS) and offline (OFS) sociability. We considered the possibility that variations in the use of technology and socio-economic variations shape the level of influence of ONS and OFS on WB and SI. We also considered the possibility of a “spillover effect" between ONS and OFS (Mesch et al., 2012). We combined "user-technology interface" models from communication studies and the social diversification hypothesis (Mesch et al., 2012) and considered the possibility that a "spillover" conceptualization enables to clarify the relationship between ONS and OFS on one hand, and WB and SI on the other.

Our findings provide mixed support for our hypotheses. On the one hand, it is clear that online exposure to social clues and messages is a strong predictor of positive evaluations for individuals' wishing to be socially involved. The study's findings indicate that ONS is a strong factor in increasing one's happiness levels because ONS is a strong predictor of both WB and SI. These findings are in line with Boyd's (2008) concept of "networked publics" as a source of increased social activity. The study also points to the fact that sociable individuals are likely to use both the virtual and the physical realm to seek sociable relationships. Hence, it is obvious that individuals with strong sociability needs are likely to use ONS to further strengthen the ties, which are already strong in the offline physical realm, such as friends, family and other social connections. The study's findings therefore confirm the assumption driven from the social diversification hypothesis (Mesch et al., 2012) supporting the notion that the use of online media of sociability fortifies and does not weaken offline social connections. More important, the findings provide evidence that whether or not users are frequent virtual "socializers", their use of ONS seems to be raising levels of WB and SI. The study's findings therefore refute critical points made regarding the overwhelming power of online communities to threaten existing social connections in the physical realm where we still and will keep maintaining and enjoying our personal and intimate relationships (Best et al., 2014; Song \& Kim, 2006). In fact, they support the importance of belonging in shaping our experiences both with online and offline communication media (Markopoulos, 2009). ONS though ensures higher WB when individuals "allow" technology to increase individual happiness by removing obstacles affecting individuals' sense of belonging and connectivity as pointed by Spahn (2015). In summary, the comparison between WB and SI suggests that when online channels are used for sociability they can provide a significant venue for increased happiness on two dimensions-overall WB and SI. The context of use modified though these effects. Individual level variations on both WB and SI reflect apparently the extent to which individuals are able and willing to form sociable situations.

Nonetheless, the study's findings also indicate that while ONS has a strong and significant effect on WB and social impact, this is not the case regarding 
OFS. These findings refute the assumption of interchangeability between ONS and OFS. There are two possible explanations to this finding. First, offline sociability is often infiltrated by professional and/or community related obligations, making it harder for individuals to feel happy about offline connectivity. Second, sociable users may have different motivations and views regarding the best way to satisfy their sociability needs. While they remain aware that the online space may increase their social connections, they may still prefer offline settings to do so. Here, the role of context variables (Mesch et al., 2012) and need for belonging (Burke \& Kraut, 2016; Markopoulos, 2009) represent important moderating factors.

As suggested in this study, some context-related constraints, such as physical and time resources that limit the use of OFS, may increase the use of ONS outlets. For example, for those individuals with reduced time resources, such as parental responsibilities and older age, ONS compensates the users' potential to restore their needs for belonging and sociability and increase the odds for WB and SI (Bouhnik \& Mor, 2014). These findings assess that context variables are important in understanding users' preferences for ONS confirming the theoretical premises of the Social Diversification Hypothesis (Mesch et al., 2012). Finally, the study's findings indicate that the frequency of Internet use for online connectivity does not by itself generate and/or prompt the use of ONS. Whether or not users are frequent virtual "socializers", the use of ONS seems to be raising their levels of WB and SI.

\section{Limitations and recommendation for future studies}

The study's contribution is limited due to three factors. First, the study does not include different types of ONS and OFS. The differences between kinship social ties and/or friendship and/or professional ties may provide important insights into the extent of individual preferences for online and/or offline venues to fill their sociability needs. Second, the study did not control for distinct types of media uses. Differences in social media specific effects on ONS and OFS may provide farther explanation to the findings. Finally, the data set used for the study is not up-to-date and hence the results may not be particularly accurate. Future studies should also consider the extent to which users prefer online/offline venues to accomplish additional goals, such as health, dating, donating to philanthropic causes and the like. Finally, it could be helpful to tap into the nature of constraints that increase individuals' preferences for ONS. Disabilities, for example, as well as socioeconomic gaps or even ethnic and cultural codes may affect an individual's empowerment levels, which are often necessary for successfully managing demanding offline social situations.

\section{Conclusion}

We conclude that understanding the role of ONS in increasing WB and SI necessitates conducting comparative studies with large and representative samples in order to tap into the diverse range of factors that place possible constraints on 
individual preferences for ONS vs. OFS. Moreover, a wider theoretical perspective is necessary to extend the existing knowledge and provide a "balanced" approach that considers both the pull and the push factors in the preference for ONS vs. OFS. The extent to which virtual reality affects our levels of happiness is after all a common ground for all individuals seeking to be socially involved and happy. In our interpretation, the results clearly indicate that modern society has somehow diminished possibilities for OFS and increased the importance of online connectivity to compensate for the lack of potential access to offline sources of connectivity (Mesch et al., 2012).

\section{Conflicts of Interest}

The authors declare no conflicts of interest regarding the publication of this paper.

\section{References}

Anand, P. (2016). Happiness Explained: What Human Flourishing Is and What We Can Do to Promote It. Oxford: Oxford University Press.

Barnard, Y., Bradley, M. D., Hodgson, F., \& Lloyd, A. D. (2013). Learning to Use New Technologies by Older Adults: Perceived Difficulties, Experimentation Behaviour and Usability. Computers in Human Behavior, 29, 1715-1724.

https://doi.org/10.1016/j.chb.2013.02.006

Baumeister, R. F., \& Leary, M. R. (1995). The Need to Belong: Desire for Interpersonal Attachments as a Fundamental Human Motivation. Psychological Bulletin, 117, 497-529. https://doi.org/10.1037/0033-2909.117.3.497

Best, P., Manktelow, R., \& Taylor, B. (2014). Online Communication, Social Media and Adolescent Wellbeing: A Systematic Narrative Review. Children and Youth Services Review, 41, 27-36. https://doi.org/10.1016/j.childyouth.2014.03.001

Bondad-Brown, B. A., Rice, R. E., \& Pearce, K. E. (2012). Influences on TV Viewing and Online User-Shared Video Use: Demographics, Generations, Contextual Age, Media Use, Motivations, and Audience Activity. Journal of Broadcasting \& Electronic Media, 56, 471-493. https://doi.org/10.1080/08838151.2012.732139

Bouhnik, D., \& Mor, D. (2014). Gender Differences in the Moral Judgment and Behavior of Israeli Adolescents in the Internet Environment. Journal of the Association for Information Science \& Technology, 65, 551-559. https://doi.org/10.1002/asi.22979

Boyd, D. M. (2008). Taken Out of Context: American Teen's Sociality in Networked Publics. Berkeley, CA: ProQuest.'

Burke, M., \& Kraut, R. E. (2016). The Relationship between Facebook Use and Well-Being Depends on Communication Type and Tie Strength. Journal of Computer-Mediated Communication, 21, 265-281. https://doi.org/10.1111/jcc4.12162

Chopik, W. J., Rikard, R. V., \& Cotten, S. R. (2017). Individual Difference Predictors of ICT Use in Older Adulthood: A Study of 17 Candidate Characteristics. Computers in Human Behavior, 76, 526-533. https://doi.org/10.1016/j.chb.2017.08.014

Das, B., \& Sahoo, D. S. (2011). Social Networking Sites-A Critical Analysis of Its Impact on Personal and Social Life. International Journal of Business and Social Science, 2, 222-229.

Davis, K. (2012). Friendship 2.0: Adolescents' Experiences of Belonging and Self-Disclosure 
Online. Journal of Adolescence, 35, 1527-1536.

https://doi.org/10.1016/j.adolescence.2012.02.013

Dolev-Cohen, M., \& Barak, A. (2013). Adolescents' Use of Instant Messaging as a Means of Emotional Relief. Computers in Human Behavior, 29, 58-63. https://doi.org/10.1016/j.chb.2012.07.016

Eagly, A. H. (1983). Gender and Social Influence: A Social Psychological Analysis. American Psychologist, 38, 971-981. https://doi.org/10.1037/0003-066X.38.9.971

Ellison, N. B., Steinfield, C., \& Lampe, C. (2007). The Benefits of Facebook "Friends": Social Capital and College Students' Use of Online Social Network Sites. Journal of Computer-Mediated Communication, 12, 1143-1168. https://doi.org/10.1111/j.1083-6101.2007.00367.x

Fioravanti, G., Dèttore, D., \& Casale, S. (2012). Adolescent Internet Addiction: Testing the Association between Self-Esteem, the Perception of Internet Attributes, and Preference for Online Social Interactions. Cyberpsychology, Behavior, and Social Networking, 15, 318-323. http://doi.org/10.1089/cyber.2011.0358

Grant, A. E., Guthrie, K. K., \& Ball-Rokeach, S. J. (1991). Television Shopping: A Media System Dependency Perspective. Communication Research, 18, 773-798. https://doi.org/10.1177/009365091018006004

Green, M., \& Brock, T. C. (2008). Antecedents and Civic Consequences of Choosing Real versus Ersatz Social Activities. Media Psychology, 11, 566-592. https://doi.org/10.1080/15213260802491994

Gross, E. F. (2009). Logging on, Bouncing Back: An Experimental Investigation of Online Communication Following Social Exclusion. Developmental Psychology, 45, 1787-1793. https://doi.org/10.1037/a0016541

Hampton, K., Goulet, L. S., Rainie, L., \& Purcell, K. (2011). Social Networking Sites and Our Lives (Vol. 1). Washington DC: Pew Internet \& American Life Project.

Heo, J., Chun, S., Lee, S., Lee, K. H., \& Kim, J. (2015). Internet Use and Well-Being in Older Adults. Cyberpsychology, Behavior, and Social Networking, 18, 268-272. http://doi.org/10.1089/cyber.2014.0549

Heravi, A., Mubarak, S., \& Choo, K. K. R. (2018). Information Privacy in Online Social Networks: Uses and Gratification Perspective. Computers in Human Behavior, 84, 441-459. https://doi.org/10.1016/j.chb.2018.03.016

Hsu, M. H., Chang, C. M., \& Yen, C. H. (2011). Exploring the Antecedents of Trust in Virtual Communities. Behavior \& Information Technology, 30, 587-601. https://doi.org/10.1080/0144929X.2010.549513

Kalpidou, M., Costin, D., \& Morris, J. (2011). The Relationship between Facebook and the Well-Being of Undergraduate College Students. Cyberpsychology, Behavior, and Social Networking, 14, 183-189. http://doi.org/10.1089/cyber.2010.0061

Kim, Y. C., \& Jung, J. Y. (2017). SNS Dependency and Interpersonal Storytelling: An Extension of Media System Dependency Theory. New Media \& Society, 19, 1458-1475. https://doi.org/10.1177/1461444816636611

Ko, H. C., \& Kuo, F. Y. (2009). Can Blogging Enhance Subjective Well-beINg through Self-Disclosure? CyberPsychology \& Behavior, 12, 75-79. http://doi.org/10.1089/cpb.2008.016

Koles, B., \& Nagy, P. (2012). Facebook Usage Patterns and School Attitudes. Multicultural Education \& Technology Journal, 6, 4-17. https://doi.org/10.1108/17504971211216283

Kwon, K. H., Stefanone, M. A., \& Barnett, G. A. (2014). Social Network Influence on On- 
line Behavioral Choices: Exploring Group Formation on Social Network Sites. American Behavioral Scientist, 58, 1345-1360. https://doi.org/10.1177/0002764214527092

Mano, R. (2014). Social Media, Social Causes, Giving Behavior and Money Contributions. Computers in Human Behavior, 31, 287-293. https://doi.org/10.1016/j.chb.2013.10.044

Mano, R. (2015). Online Health Information, Situational Effects and Health Changes among E-Patients in Israel: A “Push/Pull” Perspective. Health Expectations, 18, 2489-2500. https://doi.org/10.1111/hex.12218

Markopoulos, A. (2009). Awareness Systems and the Role of Social Intelligence. AI \& Society, 24, 115-122. https://doi.org/10.1007/s00146-009-0194-5

McAndrew, F. T., \& Jeong, H. S. (2012). Who Does What on Facebook? Age, Sex, and Relationship Status as Predictors of Facebook Use. Computers in Human Behavior, 28, 2359-2365. https://doi.org/10.1016/j.chb.2012.07.007

Mesch, G., Mano, R., \& Tsamir, J. (2012). Minority Status and Health Information Search: A Test of the Social Diversification Hypothesis. Social Science \& Medicine, 75, 854-858. https://doi.org/10.1016/j.socscimed.2012.03.024

Mesch, G. S., \& Talmud, I. (2007). Similarity and the Quality of Online and Offline Social Relationships among Adolescents in Israel. Journal of Research on Adolescence, 17, 455-465. https://doi.org/10.1111/j.1532-7795.2007.00529.x

Neuman, J. H., Baron, R. A., Einarsen, S., Hoel, H., Zapf, D., \& Cooper, C. (2011). Social Antecedents of Bullying: A Social Interactionist Perspective. In S. Einarsen, H. Hoel, D. Zapf, \& G. Cooper (Eds.), Bullying and Harassment in the Workplace: Developments in Theory, Research, and Practice (2nd ed., pp. 201-225). Boca Raton, FL: CRC Press.

Pai, P. Y., \& Tsai, H. T. (2011). How Virtual Community Participation Influences Consumer Loyalty Intentions in Online Shopping Contexts: An Investigation of Mediating Factors. Behavior \& Information Technology, 30, 603-615.

https://doi.org/10.1080/0144929X.2011.553742

Papacharissi, Z., \& Mendelson, A. (2011). 12 Toward a New(er) Sociability: Uses, Gratifications and Social Capital on Facebook. In S. Papathanassopoulos (Ed.), Media Perspectives for the 21st Century (pp. 212). Abingdon-on-Thames: Routledge.

Pew Research Center (2012). Health Tracking Survey. Washington DC: Pew Research Center.

Raacke, J., \& Bonds-Raacke, J. (2008). MySpace and Facebook: Applying the Uses and Gratifications Theory to Exploring Friends-Networking Sites. Cyberpsychology, Behavior and Social Networking, 11, 169-174. http://doi.org/10.1089/cpb.2007.0056

Rauch, S. M., Strobel, C., Bella, M., Odachowski, Z., \& Bloom, C. (2014). Face to Face versus Facebook: Does Exposure to Social Networking Web Sites Augment or Attenuate Physiological Arousal among the Socially Anxious? Cyberpsychology, Behavior and Social Networking, 17, 187-190. http://doi.org/10.1089/cyber.2012.0498

Reinecke, L., \& Trepte, S. (2014). Authenticity and Well-Being on Social Network Sites: A Two-Wave Longitudinal Study on the Effects of Online Authenticity and Positivity Bias in Communication. Computers in Human Behavior, 30, 95-102. https://doi.org/10.1016/j.chb.2013.07.030

Ren, Y., Harper, F. M., Drenner, S., Terveen, L., Kiesler, S., Riedl, J., \& Kraut, R. E. (2012). Building Member Attachment in Online Communities: Applying Theories of Group Identity and Interpersonal Bonds. MIS Quarterly, 36, 841-864.

https://doi.org/10.2307/41703483

Romero, N., Markopoulos, P., van Baren, J., de Ruyter, R., Jsselsteijn W., \& Farshchian, B. (2007). Connecting the Family with Awareness Systems. Personal Ubiquity Computers, 11, 299-312. https://doi.org/10.1007/s00779-006-0089-0 
Rosen, L. D., Whaling, K., Rab, S., Camer, L. M., \& Cheever, N. A. (2013). Is Facebook Creating "iDisorders"? The Link between Clinical Symptoms of Psychiatric Disorders and Technology Use, Attitudes and Anxiety. Computers in Human Behavior, 29, 1243-1254. https://doi.org/10.1016/j.chb.2012.11.012

Ross, C., Orr, E. S., Sisic, M., Arseneault, J. M., Simmering, M. G., \& Orr, R. R. (2009). Personality and Motivations Associated with Facebook Use. Computers in Human Behavior, 25, 578-586. https://doi.org/10.1016/j.chb.2008.12.024

Schöbel, J., Pryss, R., Schickler, M., Ruf-Leuschner, M., Elbert, T., \& Reichert, M. (2016, June). End-User Programming of Mobile Services: Empowering Domain Experts to Implement Mobile Data Collection Applications. Proceedings of the 2016 IEEE International Conference on Mobile Services, San Francisco, 27 June-2 July 2016, 1-8. https://doi.org/10.1109/MobServ.2016.11

Selfhout, M. H., Branje, S. J., Delsing, M., ter Bogt, T. F., \& Meeus, W. H. (2009). Different Types of Internet Use, Depression, and Social Anxiety: The Role of Perceived Friendship Quality. Journal of Adolescence, 32, 819-833.

https://doi.org/10.1016/j.adolescence.2008.10.011

Shen, K. N., Yu, A. Y., \& Khalifa, M. (2010). Knowledge Contribution in Virtual Communities: Accounting for Multiple Dimensions of Social Presence through Social Identity. Behavior \& Information Technology, 29, 337-348. https://doi.org/10.1080/01449290903156622

Shklovski, I., Kraut, R. E., \& Cummings, J. (2008). Keeping in Touch by Technology: Maintaining Friendships after a Residential Move. Proceedings of the 2008 SIGCHI Conference on Human Factors in Computing Systems, Florence, April 2008, 807-816. https://doi.org/10.1145/1357054.1357182

Song, J., \& Kim, Y. J. (2006). Social Influence Process in the Acceptance of a Virtual Community Service. Information Systems Frontiers, 8, 241-252. https://doi.org/10.1007/s10796-006-8782-0

Spahn, A. (2015). Can Technology Make us Happy? Ethics, Spectator's Happiness and the Value of Achievement. In J. Søraker, J. W. Van der Rijt, J. de Boer, P. H. Wong, \& P. Brey (Eds.), Well-Being in Contemporary Society (pp. 93-113). Cham: Springer. https://doi.org/10.1007/978-3-319-06459-8_6

Stefanone, M. A., Kwon, K. H., \& Lackaff, D. (2012). Exploring the Relationship between Perceptions of Social Capital and Enacted Support Online. Journal of Computer Mediated Communication, 17, 451-466. https://doi.org/10.1111/j.1083-6101.2012.01585.x

Thelwall, M. (2008). Social Networks, Gender, and Friending: An Analysis of My Space Member Profiles. Journal of the American Society for Information Science and Technology, 59, 1321-1330. https://doi.org/10.1002/asi.20835

Tufekci, Z. (2008). Can you See Me Now? Audience and Disclosure Regulation in Online Social Network Sites. Bulletin of Science, Technology \& Society, 28, 20-36. https://doi.org/10.1177/0270467607311484

Valkenburg, P. M., Peter, J., \& Schouten, A. P. (2006). Friend Networking Sites and Their Relationship to Adolescents' Well-Being and Social Self-Esteem. CyberPsychology \& Behavior, 9, 584-590. http://doi.org/10.1089/cpb.2006.9.584

Van Baren, J., Jsselsteijn, W. A., Markopoulos, P., Romero, N., \& de Ruyter, B. (2004). Measuring Affective Benefits and Costs of Awareness Systems Supporting Intimate Social Networks. In A. Nijholt, \& T. Nishida (Eds.), Proceedings of 3rd Workshop on Social Intelligence Design. (pp. 13-19). Enschede: CTIT.

Walton, G. M., Cohen, G. L., Cwir, D., \& Spencer, S. J. (2012). Mere Belonging: The Power of Social Connections. Journal of Personality and Social Psychology, 102, 513-532. 
https://doi.org/10.1037/a0025731

Yamamoto, M. (2011). Community Newspaper Use Promotes Social Cohesion. Newspaper Research Journal, 32, 19-33. https://doi.org/10.1177/073953291103200103 